\title{
Adapting the depression component of WHO Mental Health Gap Intervention Guide (mhGAP-IG.v2) for primary care in Shenzhen, China: a DELPHI study
}

Kendall Searle ${ }^{1^{*}}$ (D), Grant Blashki ${ }^{2}$, Ritsuko Kakuma ${ }^{3}$, Hui Yang ${ }^{4}$, Shurong Lu ${ }^{2}$, Baoqi Li ${ }^{5}$, Yingying Xiao ${ }^{5}$ and Harry Minas ${ }^{1}$

\begin{abstract}
Background: Primary care doctors in Shenzhen, China are increasingly expected to identify and prevent depressive disorder; however, they have received limited mental health training and community healthcare centres (CHC) do not provide standardised protocols for the diagnosis and care of depressive disorder. The World Health Organization's mental health gap intervention guide, version 2 (mhGAP-IG.v2) is a decision support tool for non-specialists for the assessment, management and follow-up of mental, neurological and substance use disorders (including depressive disorder). Given that mhGAP-IG.V2 is a generic tool, it requires adaptation to take account of cultural differences in depression presentation and unique characteristics of China's emergent mental health system.
\end{abstract}

Methods: A two-round, web-based, Delphi survey was conducted. A panel of primary care doctors from Shenzhen, were invited to score their level of agreement with 199 statements (arranged across 10 domains) proposing changes to the content and structure of mhGAP-IG.v2 for use in Shenzhen. Consensus was predefined as $80 \%$ panelists providing a rating of either "somewhat agree/definitely agree", or "definitely disagree/somewhat disagree" on a five-point scale for agreement.

Results: $79 \%$ of statements received consensus with a mean score of 4.26 (i.e. "somewhat agree"). Agreed adaptations for mhGAP-IG.V2 included:- an assessment approach which considers a broader spectrum of depression symptoms and reflects the life course of disease; incorporating guidance for screening tool usage; clarifying physicians' roles and including referral pathways for intersectorial care with strong family involvement; aligning drug treatment with national formularies; stronger emphasis of suicide prevention throughout all sections of the guide; contextualizing health education; reflecting a person-centred approach to care. Panelists chose to maintain diagnostic and treatment advice for bipolar patients experiencing a depressive episode as in the current guide.

Conclusions: An adapted mhGAP-IG.v2 for depression recognises China's cultural and contextual needs for assessment guidance; unique primary healthcare system organization, priorities and treatment availability; and diverse

\footnotetext{
*Correspondence: k.searle2@student.unimelb.edu.au

${ }^{1}$ Global and Cultural Mental Health Unit, Centre for Mental Health, School

of Population and Global Health, University of Melbourne, Parkville, VIC

3010, Australia

Full list of author information is available at the end of the article
} original author(s) and the source, provide a link to the Creative Commons licence, and indicate if changes were made. The images or other third party material in this article are included in the article's Creative Commons licence, unless indicated otherwise in a credit line to the material. If material is not included in the article's Creative Commons licence and your intended use is not permitted by statutory regulation or exceeds the permitted use, you will need to obtain permission directly from the copyright holder. To view a copy of this licence, visit http://creativecommons.org/licenses/by/4.0/. The Creative Commons Public Domain Dedication waiver (http://creativeco mmons.org/publicdomain/zero/1.0/) applies to the data made available in this article, unless otherwise stated in a credit line to the data. 
psychosocial educational needs. An adapted mhGAP-IG.V2 could both inform the future training programs for primary care in Shenzhen and also offer an additional mental health resource for non-specialists in other countries.

Keywords: Depressive disorder, Mental health gap intervention guide (mhGAP-IG.v2), Delphi, Adaptation, Conceptualisation, Primary care, Intersectorial care, World Health Organization (WHO), China, Shenzhen

\section{Background}

The Healthy China 2030 Plan [1] outlines China's 21st Century vision for healthcare and creates a favorable policy environment for mental health system reform of both national and global significance [2, 3]. At its core, it acknowledges the symbiotic relationship between a healthy working population and economic success [4]. It embodies key values of the United Nations' Sustainability agenda $[2,5]$ and aligns with the latest global thinking on "person-centered, integrated care" [6-9]. Importantly, for a country with a sizable mental health treatment gap, where the vast majority of those with an identifiable mental health condition do not receive care $[10,11]$, the plan prioritizes the need to improve mental health awareness and prevention along with ready access to mental health services [12].

Shenzhen is a thriving metropolitan city located in Guangdong Province of China, just across the causeway from Hong Kong. Its population has rapidly expanded from 10.42 million people in 2010 to 17.56 million in 2020 with an average annual growth rate of $5.36 \%$ [13]. It was one of China's first special economic zones and is nationally renowned for its progressive socioeconomic reforms $[14,15]$ which has transformed the region into a global commercial hub. Aware of increasing rates of mental disorders overall [16-18] and above national levels of prevalence for depressive disorder in key working and vulnerable populations [17, 19-23] (i.e. above 7.4\%) [24], the local health authority committed to improving the recognition and prevention of common mental disorders within its developing primary healthcare sector[25]. Importantly, they invested in the upskilling of the GP workforce [26-28] and sought to implement the service of at least one doctor with a mental health certification in each community health centre (CHC) by 2020 [29]. Findings from qualitative research conducted with primary healthcare leaders in Shenzhen [30], however, found that along with improved professional development, doctors at $\mathrm{CHCs}$ also needed better access to diagnostic guidelines and protocols for depression care.

Guidelines can be considered as a "synthesis of evidence" that have been shaped into "practice-oriented recommendations" and represent the "highest quality opportunity" for patient care [31]. The sharing of guideline information, from one setting to another, avoids duplication of research efforts and optimizes on resource in underfunded settings [32,33] and, as such, has become a widely accepted approach for global progress in healthcare [34]. One such guideline, the World Health Organization (WHO), Mental Health Gap Intervention Guide (mhGAP-IG) [35] offers community health care centers in Shenzhen a rigorously developed and internationally approved resource $[36,37$ ] with which to train doctors on the assessment, management and follow-up of depression patients and other priority mental health conditions $[38,39]$. Now freely available in its second edition (although not in Mandarin Chinese), mhGAP-IG.v2 [40] incorporates both evidence-based and financially affordable treatment options suitable for use in community and resource-poor settings.

mhGAP-IG.v2, however, is a generic tool and adoption needs to be accompanied by prior consideration of its context of use: "the physical, organizational, institutional and legislative structures that enable and constrain, resource and realize, people and procedures" [41, 42]. Whilst a universal approach to the adaptation of mhGAP-IG is still evolving [43], it is generally agreed upon that the consultation of end-users is integral for the appropriate adaptation and enhancement of future implementation [38, 44, 45]. These pre-requisites are particularly relevant to China, where substantive organizational and operational change to the national healthcare system have produced a model of primary healthcare delivery unique to its developmental context.

For example, mhGAP-IG embodies aspirational global standards in mental health practice which have been shaped by an established acceptance and confidence for the close involvement of primary healthcare in the diagnosis and management of mental health conditions in upper income countries [7, 46-48]. In contrast, primary healthcare doctors in China administer care without the legal authority to diagnose severe mental health conditions [30,49]. Neither do CHCs experience the operational autonomy of western clinics. Instead, they are tied into the management system of their district hospital which controls both their budget and drug formulary [50]. Whilst Chinese psychiatrists were involved in the drafting of the initial mhGAP-IG, primary care representatives were not included in the consultation process and the guide may omit vital procedural or referral information in keeping with the realities of primary care prescribing practice. 
Nor can the impact of culture on how different countries perceive, realise and respond to mental disorders at both a personal and system level, be ignored [51]. Sociopolitical events in China's past have conditioned currentday attitudes and behaviors that can act as barriers to the expression of, and health seeking for, depression [52-54]. mhGAP-IG.v2 is closely aligned to international classification systems (e.g. ICD 10, DSM-IV) which were originally developed according to western presentation of disease in hospital settings and may not be sensitive enough to pick up cultural subtleties of disease presentation in community-based settings.

Whilst over 90 countries have seen the uptake of mhGAP-IG [39], publications focusing on its adaptation for country-specific needs are in short supply. The Programme for Improving Mental Health Care (PRIME) initiated investigations into the use, adaptation and integration of mhGAP-IG resources into the primary care systems across low and middle income countries $[55,56]$. Since then, researchers based in Africa [38, 57-59] and Nepal [45] have endeavored to either contextualize or provide a culturally sensitive translation [59] of the guide. This was commonly achieved by engaging key stakeholders in a multi-stepped review, generally led by mental health specialists or a discrete research team $[38,57,58]$ and including Primary care representatives in at least one stage of the adaptation process (i.e. as participants of preliminary qualitative focus groups $[38,57]$ for prototype testing of a training program [58].

This research uses the Delphi Approach, an established consensus methodology (see methods section for more details), to adapt the depression component of the mhGAP-IG.v2 for use by doctors working in community healthcare centres in Shenzhen, to take into account local culture and health system structure and reform. It signifies the completion of three phases of research, all of which have been conducted "with primary care, for primary care": from its conception with primary care leaders to explore the current needs for the improved management of depressive disorder in $\mathrm{CHCs}$ [30]; to immersive workshops with primary care leaders to compare the depression guidelines with current conceptualisations of depression and clinical practice (awaiting publication); through to this Delphi study with the broader primary care community in Shenzhen.

It is unique amongst these adaptation studies by its intentional focus on the depression component only (i.e. one chapter of the guide). With the exception of one study in Nepal [45], which focused on dementia, other key studies in this field were directed at reviewing the whole guide [38, 57-59]. The advantage of this depression-only approach is the breadth and depth of items, generated from highly focused preliminary research that can be put forward for consensus testing. As such, there is potential to obtain the systematic consensus on guideline adaptations across a range of topical mental health system, depression symptom presentation and other complex care-related concepts, which have not been previously explored in this way. Importantly, it seeks to support local and global aspirations of reducing the mental health treatment gap in China.

In summary, this study occupies a vital bridge between international guidance on best practice for depression care and making knowledge relevant and acceptable for the end-user of the guide. To the best of our knowledge, it is the only mhGAP-IG.v2 adaptation study initiated in China within the primary healthcare sector.

\section{Methodology}

\section{The Delphi approach}

Delphi is a systematic review process that obtains a consensus view on a matter from a panel of experts. An expert can be anyone who has intimate knowledge, practice, experience or need relating to the topic of interest. The panel need not be very large [60] nor need to establish statistical power [61] but key conditions must be met, including diversity of expertise; independent and decentralised decision making; and aggregation of results by an objective research facilitator [62]. Delphi has been widely used by the mental health sector and often when other sources of evidence is unavailable [63]; for example, to define standards of practice for a mental health workforce [64] or to assist with the content development of mental health training programs $[65,66]$. This research applied the Delphi approach to establish a primary care panel to participate in two rounds of a web-based, selfcompletion survey (in Mandarin Chinese). Panelists were asked to review and score their level of agreement with a series of statements proposing adaptations to the content and structure of the mhGAP-IG.v2 to contextualise it for use in China.

\section{Panel recruitment}

A Shenzhen-based steering committee of seven Primary Healthcare Leaders (two from the core urban area; four from the suburban areas; one from the city border districts) facilitated recruitment and provided advice on local conditions. Leaders had been identified by their prior graduation from The Shenzhen General Practice Leadership Training Programme [67], an international educational collaboration between Monash University, Australia, and the Shenzhen Health Capacity Building and Continuing Education Centre, the regulatory body and vocational training provider responsible for the qualification and certification of primary care doctors in Shenzhen. They circulated survey information 
through their district primary healthcare network, distributed and collected the plain language statements and informed consent forms in accordance with ethics requirements. The research co-ordinator (KAS) finalised enrolment by providing each panelist with a confidential and password-protected link to the live online survey. She was also responsible for intra-wave analysis and feedback to panel members.

\section{Inclusion/exclusion criteria}

Doctors working in $\mathrm{CHC}$ who saw 50 + patients each week were invited to join the panel. Doctors required either a self-professed interest in mental health and/or a primary healthcare mental health certificate (i.e. did not need to be actively diagnosing depression patients as this function is considered to be the role of specialists in China). Survey materials were provided in Mandarin Chinese; thus English was not a pre-requisite. Panel heterogeneity was achieved by recruiting doctors working in CHCs located across urban, suburban and city boarder areas of Shenzhen.

\section{Size and geographic distribution}

75 doctors (51\% Female) participated in the first wave of the survey with most panelists working in $\mathrm{CHCs}$ located in suburban areas (55\%), followed by core urban districts $(35 \%)$, then by city border districts $(11 \%)$, where international academic relationships are least well developed. Fewer panelists, 59 in total, participated in Wave 2 (retention rate, $79 \%$ ). Despite the dropout, the overall percentage contribution by area and gender remained similar across both waves of the survey. Doctors with a mental health certificate were more likely to participate in both waves of the survey.

\section{Questionnaire development}

The statements were generated through the thematic analysis of bilingual qualitative research regarding the acceptability, applicability and transferability of mhGAPIG.v2 use in CHCs as conducted previously by this group with primary care leaders (awaiting publication). The statements were organized into ten domains relating to: (i) person-centred concepts of care; (ii) depression presentation; (iii) screening instruments; (iv) healthcare interconnectivity; (v) drug treatment; (vi) mania; (vii) communicating depression; (viii) follow-up; (ix) managing patient information; and $(\mathrm{x})$ overall guide structure. Statements were translated into Mandarin, back-translated, piloted (3 CHC doctors in Shenzhen and 2 GPs/ researchers in Australia) and refined. Finally, 199 statements were put forward for testing in Wave 1.

\section{Questionnaire metrics}

Statements were scored for agreement using a five-point Likert scale where $5=$ "definitely agree"; $4=$ "somewhat agree"; $3=$ "neither agree or disagree"; $2=$ "somewhat disagree"; $1=$ "definitely disagree". Consensus was predetermined as $80 \%$ panelists scoring either a $4 / 5$ (i.e. "somewhat agree/definitely agree") or conversely $1 / 2$ (i.e. "definitely disagree/somewhat disagree") on the fivepoint Likert scale for agreement. Panel members also had the opportunity to suggest additional items to the guide or to express any reservations through some open-ended questions.

\section{Survey process}

Two waves of web-based survey were conducted using the Qualtrics Survey Platform (Wave 1: December 2019 to January 2020; Wave 2: December 2020 to February 2021). In the first wave of the survey, 152 items (76\%) met consensus. Open-ended responses were assessed and no new statements were generated. The remaining 47 statements, which did not reach consensus, were re-presented to the panel in a second wave of testing. To assist the decision making process, panelists were provided with the overall rating for each item as well as their individual rating compared with the rest of the panel. In the second wave of the survey, 6 more items received agreement bringing the final agreed number of items to 158 (accounting for $79 \%$ of all rated statements). After wave 2, doctors remained undecided on 41 items. Finally, recommendations for guideline adaptation were established by comparing consensus (and non-consensus) items against the relevant sections of the mhGAP-IG.v2. See Fig. 1.

\section{Results}

Demographics

Panelist characteristics: Overall, doctors had an average of $6+$ years of formal general practice experience. In Wave $1,15 \%$ of panelists personally held a mental health certificate and $57 \%$ had access to another GP with mental health certification within their CHC. In Wave 2, more panelists either held a mental health certificate (24\%) or had access to another GP with mental health certification (68\%). A sub-analysis confirmed that, during the course of the study, several panelists received mental health training and achieved certification as part of their health center's commitment to "one mental health GP per centre".

CHC characteristics: In general, panelists worked in a clinical team with an average of 7 to 8 doctors, although clinic size ranged widely from 1 to 20 doctors. Panelists in Wave 2 had a significantly lower patient load per week than those in Wave 1 (Wave 2: 176.3 patients/week versus Wave 1: 275 patients/week). Similarly, Wave 2 panelists 


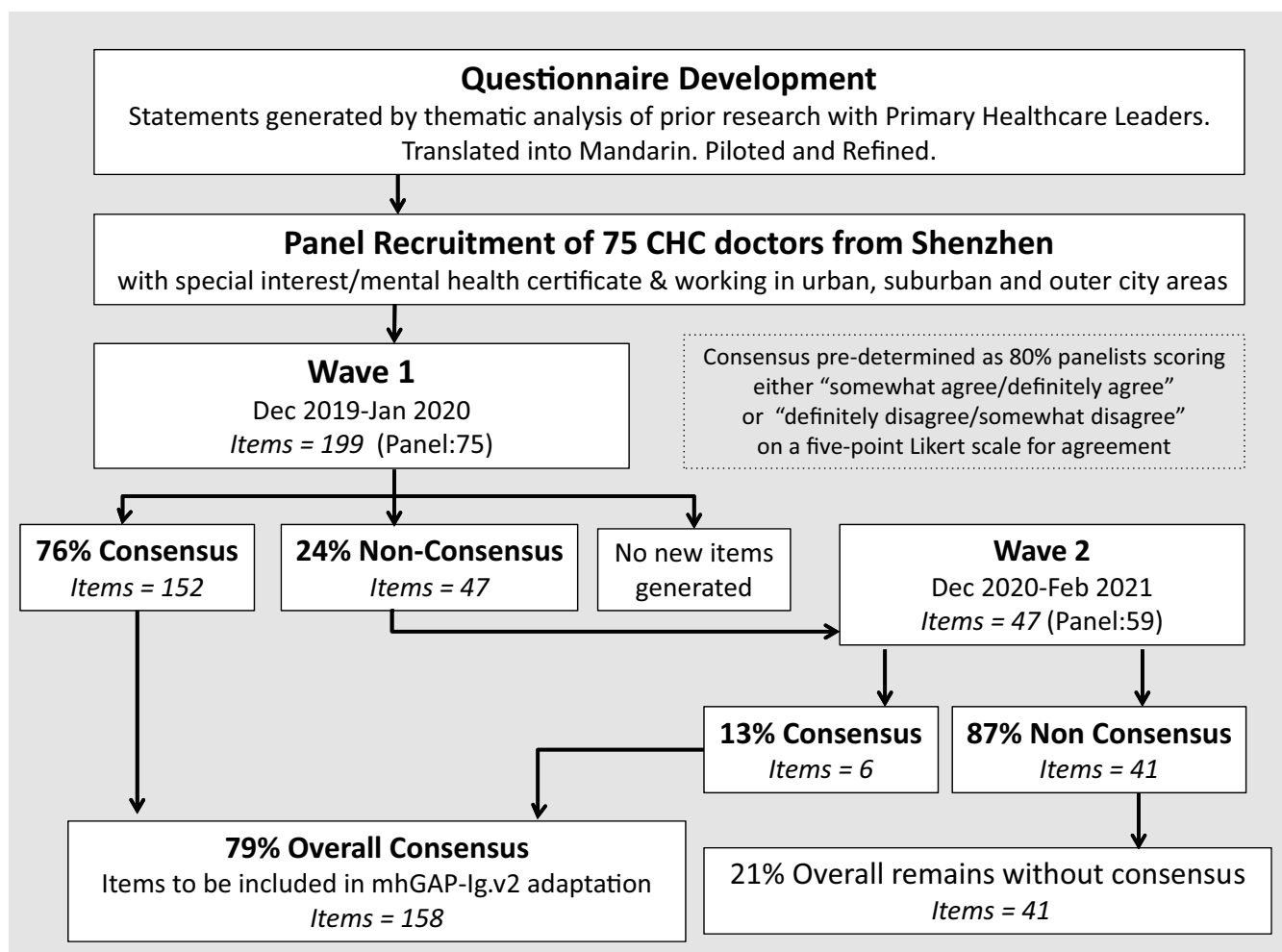

Fig. 1 The Delphi process from questionnaire development to statement consensus

also recorded fewer depression diagnoses (Wave 2: 1.9/ week versus Wave 1: 2.7/week). A sub-analysis and follow-up telephone calls with several panel members confirmed a temporal change in health seeking behavior during the one-year interim between survey waves, which coincided with the Covid-19 epidemic. During this time, people were advised not to visit the doctor (unless in emergency) and doctors focused their time on the vaccine rollout.

\section{Consensus overview}

Upon completion of research, Panelists "somewhat agreed" with 158/199 proposed adaptions to the mhGAP-IG (overall adjusted mean score: 4.26 up from 4.25 in Wave 1). The adjusted mean scores for each domain ranged from 4.05-4.65 with statements relating to "Developing a patient-centred guide" receiving the highest adjusted mean score and "Follow-up" the lowest. In Wave 1, domains for "Developing a patient-centred guide" and "Bipolar disorder" received 100\% consensus on all items. Thus the 47 items put forward for Wave 2 came from eight domains only. Further consensus was limited, with only between $17-31 \%$ of items clustered within three domains receiving further agreement. The domain with the most intra-wave movement was
"Follow-up" where the percentage consensus increased from 64 to $73 \%$ across the two waves of research. Finally, no items, from any domain, in either wave of research, were rejected outright (i.e. scored either 1 or 2 by $80 \%$ or more doctors). (See Table 1).

\section{Domain specific results}

Table 2 outlines panelists' recommendations for adaptations to mhGAP-IG.v2 based on statements that received consensus after two waves of Delphi survey. It is grouped by domain (ten in total) and listed according to decreasing mean score for overall domain agreement. Full listings of items, with and without consensus, are available as Additional file 1: Tables S3 and S4.

Of highest approval was developing a patient-centred guide. Panelists consented to an "in principal" personcentred approach to care with additional emphasis given to patient privacy, sensitivity towards patient diversity and personal events of significance. To achieve this, they supported the provision of a patient-led management plan and agreed it should include both patient-led outcomes, doctors' clinical feedback and administrative milestones. As this is not current practice in Shenzhen, they allocated responsibility for template development to be held by the $\mathrm{CHC}$ doctor with mental 
Table 1 Wave 1 \& 2 Delphi Survey Consensus by Thematic Domains

\begin{tabular}{|c|c|c|c|c|c|c|c|c|}
\hline \multirow[b]{2}{*}{ DOMAIN } & \multicolumn{3}{|c|}{$\begin{array}{l}\text { Wave } 1 \\
\text { Base: } 75 \text { panelists }\end{array}$} & \multicolumn{3}{|c|}{$\begin{array}{l}\text { Wave } 2 \\
\text { Base: } 59 \text { panelists }\end{array}$} & \multicolumn{2}{|c|}{ Overall Consensus } \\
\hline & $\begin{array}{l}\text { No. of } \\
\text { Items } \\
\text { Tested }\end{array}$ & $\begin{array}{l}\text { Consensus } \\
\%\end{array}$ & $\begin{array}{l}\text { Mean } \\
\text { Score }\end{array}$ & $\begin{array}{l}\text { No. of } \\
\text { Items } \\
\text { Tested }\end{array}$ & $\begin{array}{l}\text { Consensus } \\
\%\end{array}$ & $\begin{array}{l}\text { Mean } \\
\text { Score }\end{array}$ & $\begin{array}{l}\text { Consensus } \\
\%\end{array}$ & $\begin{array}{l}\text { Adjusted } \\
\text { Mean } \\
\text { Score }\end{array}$ \\
\hline Overall Consensus & 199 & 76 & 4.25 & 47 & 13 & 3.66 & 79 & 4.26 \\
\hline 1. Developing a Patient-Centred Guide & 18 & 100 & 4.65 & 0 & $\mathrm{Na}$ & $\mathrm{Na}$ & 100 & 4.65 \\
\hline 2. Symptom Presentation of Depression & 28 & 64 & 4.07 & 10 & 0 & 3.50 & 64 & 4.06 \\
\hline 3. Improving Access/Usage to Diagnostic Tools & 11 & 64 & 4.13 & 4 & 25 & 3.80 & 73 & 4.24 \\
\hline 4. Healthcare and Community Interconnectivity & 28 & 79 & 4.23 & 6 & 17 & 3.75 & 82 & 4.26 \\
\hline 5. Considering Pharmacological Interventions & 18 & 78 & 4.20 & 4 & 0 & 3.51 & 78 & 4.19 \\
\hline $\begin{array}{l}\text { 6. Considering Mania and Depressive Episode in } \\
\text { Bipolar Disorder }\end{array}$ & 4 & 100 & 4.59 & 0 & $\mathrm{Na}$ & $\mathrm{Na}$ & 100 & 4.59 \\
\hline $\begin{array}{l}\text { 7. Communicating Depression to Patients and } \\
\text { the Community }\end{array}$ & 29 & 90 & 4.36 & 3 & 0 & 3.77 & 90 & 4.36 \\
\hline 8. Follow-Up & 33 & 61 & 4.03 & 13 & 31 & 3.64 & 73 & 4.05 \\
\hline 9. Managing Patient Information & 11 & 82 & 4.20 & 2 & 0 & 3.73 & 82 & 4.20 \\
\hline 10. Overall Structure of an Adapted Guide & 19 & 74 & 4.06 & 5 & 0 & 3.61 & 74 & 4.06 \\
\hline
\end{tabular}

${ }^{*}$ Consensus based on $80 \%$ panel participants providing a score of either 4 or 5 (i.e. "Somewhat agree/Definitely agree") or conversely a score of 1 or 2 (i.e. “Definitely disagree/somewhat disagree") for each individual item

${ }^{*}$ Wave 2 items were drawn from all those items where consensus was not achieved in Wave 1. Additionally, no items were rejected in Wave 1 (i.e. $80 \%$ participants scoring either a 1 or a 2 (i.e. "Definitely disagree/Somewhat disagree")

health certification. They also universally agreed that guidelines should emphasize suicide as a priority concern in primary care and the active involvement of family in care. These two elements reflect unique differences between "norms" in China's primary care health system and mhGAP-IG.v2.

Panelists unanimously consented to incorporating all information in mhGAP-IG.v2 relating to differential needs for the treatment of a depressive episode in bipolar disorder. Again, they highlighted the importance of involving family in the guidelines for care by actively asking for their input regarding mania symptoms.

To be more relevant for the Shenzhen context, panelists wanted to expand the mhGAP-IG.v2 scope to approve doctors' role to educate patients, family and community members about depression as an important step to improving overall health literacy. Furthermore, they endorsed $\mathrm{CHC}$ doctors playing a leading role with monitoring suicide in the community supported by the inclusion of additional strategies. They consented to updating the section on psycho-education to further contextualise it for use in Shenzhen, with a particular need to address establishing patient trust. Panelists saw fit to use the guide to promote using an appointment system as a practical solution to improve access to doctor time.
Two key changes to mhGAP-IG.v2 were agreed upon to enhance healthcare interconnectivity and demonstrate a context-specific commitment to intersectorial care. Firstly, the flowcharts relating to referral options should encompass a wide range of medical and non-medical services (e.g. schools; police; social services; work-place support groups; voluntary organisations; other mental health support services; disabled persons federation). Secondly, family members need to be incorporated as key components of intersectorial care. Importantly, the schema of the guide should also project a sense of keeping the patient central to decision-making.

Panelists took the opportunity to expand the guidelines to provide advice on the potential use of depression screening tools to support a depression diagnosis (i.e. by whom; at what stage of care; how often; in what settings). Practical measures to improve the management of patient information were also approved, such as validating patient treatments directly with patient and/or treating doctors. Additionally, they endorsed the practice of case sharing with other doctors within the same clinic.

With regards to adapting the table of pharmacological treatments for depression, experts concurred that drug listings should provide Chinese brand names and include the latest generation products. As well as standard product indications and side effect profile information 
Table 2 Primary care recommendations for an adapted mhGAP-IG.v2

\section{DOMAIN}

Rank ordered by mean score

Developing a patient-centered guide

Depressive episodes in bipolar disorder

Communicating depression to patients and the community

Healthcare interconnectivity

Access/usage to depression questionnaires

Managing patient information

Considering pharmacological interventions for depression

\section{Primary Care Recommendations for an Adapted mhGAP-IG.v2}

Based on all items receiving consensus after two waves of Delphi survey (Wave 1: 75 CHC doctors; Wave 2: 59 CHC doctors)

1.1 Not just patient-centred but person-centred Ensure patient privacy Sensitive to events in patients life (i.e. grief) Accommodate for patient diversity

1.2 Provide a personalised patient management plan (PMP) developed in partnership with the patient flexible to evolve over time to suit patient needs outlines several strategies to elicit positive behaviour change

1.3 PMP to incorporate doctor, patient and administrative outcomes:Doctor review of treatment progress (e.g. drug side effects, treatment changes)

patient's treatment evaluation (e.g. treatment experience and engagement with therapy) administrative tracker (e.g. consultation appointments and potential referral options)

1.4 Doctor with mental health certification to develop PMP template

1.5 Address contextual differences Consider suicide risk as a priority Highlight family involvement in every stage of care Provide specific examples of patient success stories from Shenzhen

2.1 Differentiate between treatment practice for (uncomplicated) depression and depressive episode in bipolar disorder mood stabilizer required as an adjunct to antidepressant treatment

2.2 Check for symptoms of mania with the patient or with family members

3.1 Doctors to play a role in improving community awareness and health literacy

3.2 Stronger emphasis of the role of family in patient support

3.3 Include strategies for $\mathrm{CHC}$ to monitor patients at risk of suicide

3.4 Expand content of patient psychoeducation include approaches to develop patient trust (e.g. listening with empathy) address any misconceptions about the disease provide treatment success stories prepare patients for community stigma discuss the importance of treatment adherence provide advice on engagement with activities encourage attendance of follow-up appointments with $\mathrm{CHC} /$ specialists agree to a management/healthcare plan provide advice on self-care Consider implementing an appointment system

4.1 Highlight community involvement with monitoring patients at risk of suicide 4.2 Clarify referral pathways and the division of professional responsibilities 4.3 Highlight opportunities for medical and non-medical intersectorial care* 4.4 Reference involvement of family as a component of intersectorial care 4.5 Include a reminder to keep the patient central to all discussions

5.1 Recommend questionnaire usage during management and/or/both follow-up 5.2 Questionnaires conducted in a private consultation room

5.3 Doctors \& nurses can administer questionnaire (assuming training provided) 5.4 Clarify scope for tools (i.e. multiple times? non-clinic settings?)

6.1 Review a patient's history before consultation and update patient records 6.2 Supplement information from patient management system if necessary 6.3 Validate patients' treatment with specialists, other treating doctors, family members or by sighting medication

6.4 Hold regular in-clinic meetings to discuss difficult cases with other doctors

7.1 Address Dr's role with regards to monitoring and changing drug dose

7.2 Include indication and side effect profiles for each drug group

7.3 Include drug availability \& reimbursement status for each drug group

7.4 Include adherence advice for each drug group

7.5 Provide details of latest generation of drugs

7.6 Provide Chinese brand names

7.7 Add information for Benzodiazepines 
Table 2 (continued)

\begin{tabular}{|c|c|}
\hline DOMAIN & Primary Care Recommendations for an Adapted mhGAP-IG.v2 \\
\hline Symptom presentation of depression & $\begin{array}{l}\text { 8.1 Guide should "reflect a real-life consultation" } \\
\text { consider whether a patient had had a previous episode of depression } \\
\text { ascertain details of relationship problems (including grief) } \\
\text { assess patient's risk of suicide early in consultation } \\
\text { consider physical symptoms first } \\
\text { 8.2 Include triggers and risk factors for depression } \\
\text { 8.3 Diagnosis based on "a symptom spectrum rather than core symptoms alone" } \\
\text { merge both the core and additional symptoms into one listing } \\
\text { include loss of libido in symptom listing } \\
\text { order the list by good predictors of depression/commonly seen symptoms } \\
\text { provide additional details of symptom profile changes over time } \\
\text { 8.4 Structural clarity to differentiate between physical and mental symptoms } \\
\text { 8.5 Additional symptom information required for children } \\
\text { 8.6 Careful quantifications/translations required for } \\
\text { "sleeping too much" } \\
\text { "talking and moving more slowly than usual" }\end{array}$ \\
\hline Overall structure & $\begin{array}{l}\text { 9.1 Some or major restructuring needed to better reflect the context of use } \\
\text { 9.2 Emphasise intersectorial involvement including family/community network } \\
\text { 9.3 Highlight differences between depression and a depressive episode in } \\
\text { bipolar disorder } \\
\text { 9.4 Integrate follow-up and management into one continuous section } \\
\text { 9.5 Commence assessment with consideration of patients at high risk of suicide } \\
\text { 9.6 Place the patient at the centre of the guide }\end{array}$ \\
\hline Follow-up & $\begin{array}{l}\text { 10.1 Define follow-up and explain why it is necessary } \\
\text { to determine a patient's treatment status } \\
\text { to establish previous therapy/treatments received } \\
\text { to monitor current treatment side effects \& assess for improvement } \\
\text { 10.2 Explain how to assess for improvement:- i.e. itemise signs of improvement } \\
\text { 10.3 Highlight key CHC outcomes to be achieved from follow-up consultation } \\
\text { options for basic psychotherapy at CHC level } \\
\text { referral options for either psychological interventions/drug treatment } \\
\text { 10.4 Itemise modes of follow-up contact (face-to-face, telephone, electronic) } \\
\text { 10.5 Recommend preferred mode of consultation contact } \\
\text { ideally, face-to-face follow-up for all patients } \\
\text { at least, face-to-face for all those with serious conditions } \\
\text { patient's preference for non-emergency cases } \\
\text { 10.6 Frequency and duration of contact determined by depression severity, risk } \\
\text { of self harm and treatment compliance }\end{array}$ \\
\hline
\end{tabular}

" schools; police; social services; work-place support groups; voluntary sector; other mental health support services; disabled persons federation

contained within the current guide, $\mathrm{CHC}$ doctors had additional information needs to cover product availability (CHC versus hospital), reimbursement status and compliance advice. Contrary to the current focus on antidepressants only, panelists conceded to introducing information on Benzodiazepines. Importantly, they agreed that drug information should be preceded with a clarification of the $\mathrm{CHC}$ doctor's role in monitoring and changing antidepressant treatment.

Whilst Panelists struggled to come to agreement on all of the items relating to depression presentation, they consented to a conceptual change to diagnostic practice such that diagnosis should be based on a spectrum of symptoms rather than core symptoms alone. They endorsed a key structural change to the assessment section (i.e. merging core and additional symptoms into one listing). Whilst they did not concede to expanding the content of the merged listing to include anxiety and a range of depression-related behavioral symptoms (e.g.. weeping) (See additional files for non-consensus items), other agreements portrayed a preference to reflect a real life consultation and the use of risk factors to support recognition of depression. It was agreed that children would need additional information.

Several structural changes to the overall guide were recommended, particularly relating to the algorithms for follow-up practice, which do not currently resemble the $\mathrm{CHC}$ reality. Panelists approved statements to merge the management and follow-up sections of the current guide. Additional educational elements would need to be added to the new section: to define the purpose of follow-up; to explain how to assess for improvement; and to provide outcome measures such as context-specific referral options to care. Details relating to frequency, duration, and appropriate mode of follow-up contact were also needed. Panelists reinforced the need to bring suicide to 
the forefront of the guide and embed family as part of the cycle of care. Furthermore, any changes are not to deflect from the intrinsic principle of keeping patients central.

\section{Discussion}

\section{Context-specific needs for assessment guidance}

This research builds on findings from preliminary research conducted by this group with primary health care leaders in Shenzhen (awaiting publication), which confirmed CHC doctors' preference to base a depression diagnosis on "a spectrum of symptoms, rather than core symptoms alone". The agreed merger of both the core and additional symptoms into one listing in an adapted guide is symbolic of the pragmatic nature of primary care, which avoids the premature exclusion of a potential diagnosis in favor of ongoing monitoring and care. It signifies an opportunity to move away from the underlying, specialist-developed diagnostic criteria of mhGAP-IG.v2 to adopt a life course approach, befitting with primary care (i.e. that depression is a complex multi-dimensional disease where symptoms can present in any order over the course of a lifetime) [7, 68,69]. Although panelists did not endorse primary healthcare leaders' suggestions to incorporate somatic symptoms, anxiety and other behavioural indicators for depression into this listing, they agreed more generally that mhGAP-IG.v2 should inform doctors of potential risk factors which trigger depression and clarify how depression changes over time.

A key finding of this research was the consistent endorsement of modifications throughout the mhGAPIG.v2 to reinforce primary care's responsibility to detect patients at risk of suicide. In diagrammatic terms, this necessitates a reorganization of the decision-making flowcharts, to check prior history of suicide attempt early in consultation, to elevate suicidal tendencies in the symptom listing and to direct the doctor to the module for self-harm, also contained within mhGAP-IG.v2. These changes are both consistent with China's national drive to reduce suicides by $30 \%$ by 2030 [70] and necessary to address locally-based concerns of high rates of suicides in key working and vulnerable populations [71, 72]. Similarly, self-harm and suicide was identified as a priority disorder in a contextualization study in Tunisia [58].

The current version of mhGAP-IG.v2 does not provide any guidelines regarding the use of depression screeners in the routine diagnosis of depression, despite the availability and clinical use of a range of GP validated depression questionnaires in the West [73]. Context-specific findings from previous research indicates that $\mathrm{CHCs}$ in Shenzhen do not have standard access to depression screeners [30]. Panelists saw an opportunity to extend the guidance to encourage the uptake of appropriate screening tools (assuming appropriate training) in Shenzhen. They recognized that there was potential to involve nurses in the assessment process and this should be highlighted in the mhGAP-IG. The openness to consent to the inclusion of these new items into the guide perhaps reflects $\mathrm{CHCs}$ ' contemporary task-shifting needs and willingness to find solutions to improve the detection of depression.

Panelists did not seek to modify all aspects of the mhGAP-IG.v2 as demonstrated by their universal adoption of all information relating to bipolar disorder. The prevalence of bipolar disorder is reported to be low in China [74]. Preliminary research suggests that it is poorly understood by primary care doctors and is categorized as a severe mental health condition requiring specialist treatment. Panelists respected the guide's ability to fulfill a relevant knowledge gap in primary care training and chose to maintain recognition and treatment strategies to differentiate between a patient with depression and a patient with bipolar (experiencing a depressive episode).

\section{Responding to health system differences}

This research augments findings from prior research conducted by this group with primary care leaders in Shenzhen and other contextualization studies to clarify within the guide country-specific referral options and the division of medical professionals' responsibilities [38, 57, 58]. China's national health system reform aspires to integrate mental healthcare into primary care $[50,75]$. Key policy documents, however, do not provide step-by-step details on how to manage this transition [3, 76]. Whilst in many western countries, GPs have been actively involved in both the diagnosis and treatment of depression for some time $[77,78]$, these reforms represent a significant departure from current norms in China where psychiatrists are primarily responsible for diagnosis and treatment [49, 79]. The contextual updating of mhGAP-IG.v2 provides an opportunity to showcase how the newly developed role of $\mathrm{CHC}$ doctors with a certificate in mental health $[29,30]$ interfaces with current referral networks to provide the vital interconnection between the two arms of China's evolving mental healthcare system (i.e. community and hospital medicine).

The depth of this study allows panelists to endorse guide content relating to emergent pathways of care specifically those achieved by integration of primary care service with community bodies (e.g. social services, police, schools, voluntary sector, disabled persons federation), employers and family members. Panelists' preference for a strong community and family focus has both a cultural and a legal precedent. In contrast to many Western countries, China's mental health law stipulates that family members must be responsible for the care of 
family members with mental health concerns (i.e. helping to administer medication, ensuring the patient attends medical appointments, mood monitoring) $[3,49,69,76]$. Indeed, other public health interventions (e.g. mental health first aid) also harness this dynamic to recognize and support depression cases in the community [80]. Clearly, the current management and follow-up sections of mhGAP-IG.v2, which place the doctor in control of disease management, are not a good match for a health system that devolves mental wellbeing to a wider range of community actors.

\section{Accounting for locally available drug treatments}

As with other key mhGAP-IG contextualisation studies $[38,57]$, this research highlighted that antidepressant drug listings (e.g. mhGAP-IG.v2, Table 2, pg 29) need to be aligned with national formularies. In this case, where antidepressants are not standardly available in $\mathrm{CHCs}$, information regarding the site of availability (i.e. hospital versus $\mathrm{CHC}$ ) and drug-reimbursement status should be provided. Panelists also agreed to improve the currency of the guide by updating drug listings with the latest generation of selective serotonin reuptake inhibitors (SSRIs) and including brand names. Shenzhen is an affluent city, where disposable incomes can be very high [81], pharmaceutical drug representatives active and patients potentially aware of drug-options through direct-to-consumer marketing. However, including branded products within the mhGAP-IG.v2 may prove to be problematic, when guidance needs to maintain neutrality and avoid the promotion of one brand in preference to another. It also goes against local health authority thinking which aims to avoid over-prescription and patient addiction to potentially harmful drugs.

Panelists were also in consensus over the inclusion of benziodiazapine in the guide, although benziodiazapines are not indicated for depression but for anxiety. Whilst this section of the guide is about depression, in pragmatic terms, due to the high volume of anxiety patients seen in China [24] and primary care doctors' need to make decisions about patients who present both with depression and anxiety concomitantly [82], it seems appropriate that information about Benziodiazapines be provided in this section of the guide.

\section{Acceptance of person-centered guidelines}

This research was unique amongst contextualization studies in this field by testing end-user views on the inclusion of person-centered items in mhGAP-IG.v2 for use in primary care practice. According to the WHO framework for people-centred integrated care: "All people have equal access to quality health services that are coproduced in a way that meets their life course needs and respects social preferences, are coordinated across the continuum of care, and are comprehensive, safe, effective, timely, efficient and acceptable; and all carers are motivated, skilled and operate in a supportive environment" [83, 84]. Core to this vision is the "empowerment" of the patient, such that a patient's treatment preferences are respected and their treatment management plan is "co-developed" during a patient-led consultation. Panelists universally embraced the person-centered themes throughout the guide and endorsed the use and development of a patient management template. They preferred an action-orientated plan which itemizes patient-centred outcomes in a checklist format rather than the current version which uses more general terms (i.e. "assessment for improvement"; "evaluate engagement and experience in current treatment"). They allocated responsibility for template development to the doctor with a mental health certificate which brings potential benefits of further district-specific contextualization and long-term sustainability of use.

A locally-developed patient management plan would have other advantages too. As part of its strengthening of the mental health system, China is hastening to establish mental health rehabilitation services in the community [85]. Primary care doctors will increasingly work in conjunction, and overlap, with these service providers. Poor communication and coordination between services has been previously identified as a barrier to depression care [30]. Thus the development of a transportable record of follow-up, which is designed to be patient-centred and shared between service providers could ease the transition of care.

\section{Contextualizing health education}

The vast majority of statements put forward to improve psychosocial communications achieved consensus suggesting there is considerable scope to contextualize educational messages. These agreements imply a primary care appetite to provide health information and develop community awareness of depression but highlight a need for direction, grounded by local models of engagement (i.e. previous success stories) on how to achieve these goals. Many of the items correspond to the development of professional "soft skills" (e.g. listening and empathy), which, despite evidence of their positive effect on treatment outcomes [86-88], are often under-addressed in national medical school training programs [89]. A recent review, which identified complex and context-specific communication interactions between health professionals and patients in Asia (including China) also concluded that messaging must move beyond western-based approaches to develop culturally appropriate practices [90]. In Shenzhen, where patients' psychoeducation 
needs are diverse and vary by residential district, health education options will need additional consideration.

\section{Further research}

Further development needed at the local level:

(i) Training documents incorporating research findings should be drawn up and shared with local pilot centres for further consultation and testing. A special focus should be given to the development of a patient management plan with a shared use between primary care and multiple partners (including family) involved in patient rehabilitation in the community. Careful consultation with persons with lived experience is recommended to help shape the nature and content of these interactions.

(ii) Development of a training module focusing on soft skills to be incorporated into standard medical training to include a platform of communication aids to address district/demographic differences.

(iii) Qualitative research directed at exploring how primary care can step up activities to educate the community to better recognise depression and improve its treatment response.

(iv) Expanding research to consider the diagnosis and treatment of anxiety and depression comorbid with anxiety.

National information sharing: The findings from this research may not be directly applicable to other cities in China. China is made up of 34 administrative divisions (i.e. 23 provinces, four municipalities, five autonomous regions and two special administrative regions) each with their own distinctive geography and unique population demographics, area-specific disease profile, localised government arrangements and administrative priorities, and mental health and primary health system characteristics. There is also great variation in financial, infrastructure and human resources. Whilst CHCs in Shenzhen are "government owned but hospital managed", this is not the case in many other Provinces (e.g. Shanghai) where CHCs are both "government owned, and government managed" [91]. Thus, further research is recommended to explore the commonality and differences between $\mathrm{CHCs}$ in different cities and to determine how the research findings and/or the method of adaptation could be of value to other potential users of mhGAP-IG. v2. The dissemination of research via publication in relevant medical journals and at local conferences would be an important first step to generating a healthy exchange of information between sites.

Ensure a global feedback-loop: It is important that revised context-specific versions of mhGAP-IG.v2 are published for review by the international body of healthcare researchers. This opens up the feedback loop where other countries can share similar (or different) findings and contribute to the ongoing dialogue on updating global standards of care.

\section{Limitations}

Several limitations of this study are closely related to the COVID-19 pandemic, which spanned the duration of research and directly impacted research feasibility. Wave 1 research coincided with the national call to action for GP panelists to conduct COVID testing and contact tracing of approximately 1 million people who had travelled between Wuhan (the geographic source of the epidemic) and Shenzhen prior to Wuhan's lockdown [92-95]. Throughout 2020 healthcare services were heavily in demand (to administer care and support vaccine roll-out) and international relations between China and Australia deteriorated [96-99] with the following consequences:

(i) It was not practically feasible, nor ethically appropriate, to initiate the second wave of the survey during much of 2020. This delay, from a preplanned interval of one month to nearly one year, potentiated a drift in doctors' perspectives on depression (i.e. confounding) and saw health system changes (e.g. increase in doctor mental health certifications; changes within $\mathrm{CHC}$ leadership) which are hard to adjust for in the analysis.

(ii) A loss in panel retention by $21 \%$, although the rate of attrition remained higher than in many panel-based studies conducted in Western countries. Fortunately, the study design over-recruited to allow for a potential loss to follow-up, thus the final number of participants [59] was of sufficient magnitude and included a good spread of panelists from across geographic areas to substantiate findings. This remained well above the recommended minimum panel size (e.g. 10-18) [61] and number for panel stability (e.g. 23) [60] for a Delphi Study.

(iii) A pragmatic decision was taken to terminate the study after two waves of on-line survey with the result that $21 \%$ of items remained without further consensus. Whilst many Delphi studies continue to a third wave to fulfil the methodological principle of consensus testing [63], it is not unusual to conduct an adapted, two-wave Delphi study in the mental health research sector $[100,101]$ due to the cost to benefit ratio of successive waves of research. In this case, two waves of research produced only a tiny change in consensus (1\%) and it could be argued that any further research would generate smaller or near negligible changes in viewpoint. Additionally, the body of information produced by the $76 \%$ of statements achieving consensus pro- 
vides abundant, specific and detailed direction for the commencement of guideline adaptation.

This research was designed to obtain the perspectives of primary care physicians only. However, depression care cannot be provided in isolation and further development of the guide would ideally seek advice from multiple stakeholders including the specialist team that receive the referrals, the local services which strive to rehabilitate patients back into the community and, most importantly, persons who live with the day-to-day reality of the condition.

Finally, translation of some concepts/items from the source workshops may have been difficult for primary care doctors to understand. To minimise translation concerns, however, all items were back-translated by an experienced translator and tested prior to fieldwork by two bilingual doctors, working in CHCs in Shenzhen.

\section{Conclusion}

This research asserts that adaptation to mhGAP-IG.v2 is needed in order to align the content and algorithmic flow of decision making for $\mathrm{CHC}$ doctors in Shenzhen, China. Panelists gave their consent to diverge from the progenitor guide to accommodate for differences in the context-specific presentation of depression, health system organisation, primary care treatment prioritisation and access, as well as China's overall person-centered aspirations for twenty-first century care. Uniquely, they assert their preference for a guide that reflects the life course of disease and one that documents the scope of the wider mental healthcare team and family involvement. Equally panelists chose to adopt key measures already contained within the guide for the diagnosis and treatment of bipolar patients, which are outside their current standards of practice. The updating of mhGAP-IG.v2 for the Shenzhen context provides not only a contemporary training tool of local relevance for community healthcare centres but also offers other nations an additional resource to consider in the global advancement of improved treatment and care for depression.

\section{Abbreviations}

MNS: Mental, neurological and substance use disorders; MhGAP-IG.v2: Mental Health Gap Intervention Guide (version 2); CHC: Community healthcare centre; SSRIs: Selective serotonin reuptake inhibitors.

\section{Supplementary Information}

The online version contains supplementary material available at https://doi. org/10.1186/s13033-022-00523-0.

Additional file 1: Table S3. Statements achieving consensus. Table S4. Statements without consensus.
Acknowledgements

The authors would like to thank all the doctors who joined the panel and willingly found time to participate in one or both waves of research despite the many conflicting pressures put upon the health sector during the COVID-19 epidemic. The authors are deeply grateful too for the ongoing support from the seven members of the steering committee whose advice was instrumental to the successful completion of this work.

\section{Authors' contributions}

KS designed, coordinated \& conducted the Delphi study, analysed data and drafted the manuscript. The supervisory team: HM, GB, RK advised on study design and supported the research process from initiation to completion; $\mathrm{HY}$ facilitated the ongoing liaison with the primary healthcare community in Shenzhen and provided invaluable advise on cultural matters. SL provided methodological and software training for the Delphi Approach and provided culturally-sensitive translation support; BQL \& YYX, translated item statements and provided locally-based insights on how to execute and complete recruitment. All authors contributed their comments to draft manuscripts and have reviewed and approved the final manuscript.

\section{Funding}

This research received no external funding from any agency in the public, commercial, or not-for-profit sectors.

\section{Availability of data and materials}

Data is stored at the University of Melbourne. The data cannot be freely used, as the study is part of a PhD thesis, with the candidate currently working on the remaining data.

\section{Declarations}

Ethics approval and consent to participate

Ethics approval was sought and received from Human Ethics Advisory Group (HEAG) at the Melbourne School of Population and Global Health (MSPGH) in November 2019, Ethics ID:1,852,773.1

\section{Consent for publication}

Provided.

\section{Competing interests}

The authors declare that they have no competing interests.

\section{Author details}

${ }^{1}$ Global and Cultural Mental Health Unit, Centre for Mental Health, School of Population and Global Health, University of Melbourne, Parkville, VIC 3010, Australia. ${ }^{2}$ Nossal Institute for Global Health, University of Melbourne, Melbourne, VIC 3010, Australia. ${ }^{3}$ London School of Hygiene and Tropical Medicine, London WC1E 7HTE, England, UK. ${ }^{4}$ Monash Institute for Health and Clinical Education, School of Primary Health Care, Monash University, Notting Hill, VIC 3168, Australia. ${ }^{5}$ Shenzhen Guangming Hospital of the University of Chinese Academy of Sciences, Bao'an District, Shenzhen 518107, China.

Received: 27 June 2021 Accepted: 13 January 2022

Published online: 15 February 2022

\section{References}

1. Central Committee of the Communist Party of China. Outline of healthy China 2030 plan. 2016. http://www.gov.cn/zhengce/2016-10/25/conte nt_5124174.htm.

2. Liu GG, Chen X. China in transition: health, wealth, and globalisation. Lancet Public Health. 2019;4(9):e444-5.

3. Minas H. Chapter 9, The national mental health work plan 2015-2020. Anthony J. Marsella A, GA, USA, editor. USA: Springer; 2021.

4. 9th Global Conference on Health Promotion S. Healthy China 2030 (from vision to action). 2016.

5. Morton S, Pencheon D, Squires N. Sustainable Development Goals (SDGs), and their implementation: a national global framework for 
health, development and equity needs a systems approach at every level. Br Med Bull. 2017;124(1):81-90.

6. Kruk ME, Gage AD, Arsenault C, Jordan K, Leslie HH, Roder-DeWan S, et al. High-quality health systems in the Sustainable Development Goals era: time for a revolution. Lancet Glob Health. 2018:6(11):e1196-252.

7. Patel V, Saxena S, Lund C, Thornicroft G, Baingana F, Bolton P, et al. The Lancet Commission on global mental health and sustainable development. Lancet. 2018;392(10157):1553-98.

8. Liu Z, Buijsen M. Legal reflections on the evolving role of general practitioners in China's primary care: an assessment of regulatory strategies. Prim Health Care Res Dev. 2019;20:e9.

9. China Joint Study Partnership. Deepening health reform in China (Policy Summary): World Bank Group; World Health Organization; Ministry of Finance; National Health and Family Planning Commission; Ministry of Human Resources and Social Security; 2016.

10. Charlson FJ, Baxter AJ, Cheng HG, Shidhaye R, Whiteford HA. The burden of mental, neurological, and substance use disorders in China and India: a systematic analysis of community representative epidemiological studies. Lancet. 2016;388(10042):376-89.

11. Phillips MR, Zhang J, Shi Q, Song Z, Ding Z, Pang S, et al. Prevalence, treatment, and associated disability of mental disorders in four provinces in China during 2001-05: an epidemiological survey. Lancet. 2009;373(9680):2041-53

12. Li B. Tutorial for outline of the healthy China 2030 plan: National Health Commission of the People's Republic of China. Singapore: Springer Nature and People's Medical Publishing House; 2020.

13. Shenzhen Statistics Bureau. Report of the 7th Population Census. Peoples'Republic China; 2020.

14. Ni PF, Kamiya M. Chapter 1: The global value chain in Shenzhen and the Pearl Delta region. The story of Shenzhen: its economic, social and environmental transformation. Nairobi: United Nations Human Settlements Programme (UN-Habitat); 2019.

15. Mosha AC. Chapter 2: Financing the city, financing th firms and financing entrepreneurship. The story of Shenzhen: its economic, social and environmental transformation: United Nations Human Settlements Programme (UN-Habitat); 2019.

16. Gong P, Liang $\mathrm{S}$, Carlton EJ, Jiang $\mathrm{Q}, \mathrm{Wu}$ J, Wang L, et al. Urbanisation and health in China. Lancet. 2012;379(9818):843-52.

17. Wang F, Zhang QE, Zhang L, Ng CH, Ungvari GS, Yuan Z, et al. Prevalence of major depressive disorder in older adults in China: a systematic review and meta-analysis. J Affect Disord. 2018;241:297-304.

18. Zhang D, Mou J, Cheng JQ, Griffiths SM. Public health services in Shenz hen: a case study. Public Health. 2011;125(1):15-9.

19. Tang X, Tang S, Ren Z, Wong DFK. Prevalence of depressive symptoms among adolescents in secondary school in mainland China: a systematic review and meta-analysis. J Affect Disord. 2019;245:498-507.

20. Wang Q, Tian W. Prevalence, awareness, and treatment of depressive symptoms among the middle-aged and elderly in China from 2008 to 2015. Int J Health Plann Manage. 2018;33(4):1060-70.

21. He X, Wong DFK. A comparison of female migrant workers' mental health in four cities in China. Int J Soc Psychiatry. 2013:59(2):114-22

22. Mou J, Cheng J, Griffiths SM, Wong SYS, Hillier S, Zhang D. Internal migration and depressive symptoms among migrant factory workers in Shenzhen, China. J Community Psychol. 2011;39(2):212.

23. Ren F, Yu X, Dang W, Niu W, Zhou T, Lin Y, et al. Depressive symptoms in Chinese assembly-line migrant workers: a case study in the shoemaking industry. Asia Pac Psychiatry. 2019;1 1(2):e12332.

24. Huang Y, Wang Y, Wang H, Liu Z, Yu X, Yan J, et al. Prevalence of mental disorders in China: a cross-sectional epidemiological study. Lancet Psychiatry. 2019;6(3):211-24.

25. Li X, Lu J, Hu S, Cheng KK, De Maeseneer J, Meng Q, et al. The primary health-care system in China. Lancet. 2017;390(10112):2584-94.

26. Li L, Hu H, Zhou H, He C, Fan L, Liu X, et al. Work stress, work motivation and their effects on job satisfaction in community health workers: a cross-sectional survey in China. BMJ Open. 2014;4(6):e004897.

27. Blashki G, Yang H, Piterman L. General practice training in China: a multimodal experiential program provided by Australian educators. Fam Med Community Health. 2018;6(1):14-9.

28. Rao X, Lai J, Wu H, Li Y, Xu X, Browning CJ, et al. The development of a competency assessment standard for general practitioners in China. Front Public Health. 2020:8(23):1-7.
29. Xiong W, Phillips MR. Translated and annotated version of the 2015-2020 National Mental Health Work Plan of the People's Republic of China. Shanghai Arch Psychiatry. 2016;28(1):4-17.

30. Searle K, Blashki G, Kakuma R, Yang H, Zhao Y, Minas H. Current needs for the improved management of depressive disorder in community healthcare centres, Shenzhen, China: a view from primary care medical leaders. Int J Ment Health Syst. 2019;13:47.

31. Harrison MB, Légaré F, Graham ID, Fervers B. Adapting clinical practice guidelines to local context and assessing barriers to their use. CMAJ. 2010;182(2):E78-84

32. Fervers B, Burgers JS, Haugh MC, Latreille J, Mlika-Cabanne N, Paquet $L$, et al. Adaptation of clinical guidelines: literature review and proposition for a framework and procedure. Int J Qual Health Care. 2006;18(3):167-76.

33. Ollenschläger G, Marshall C, Qureshi S, Rosenbrand K, Burgers J, Mäkelä $\mathrm{M}$, et al. Improving the quality of health care: using international collaboration to inform guideline programmes by founding the Guidelines International Network (G-I-N). Qual Saf Health Care. 2004;13(6):455-60.

34. Squires JE, Graham ID, Hutchinson AM, Linklater S, Brehaut JC, Curran $\mathrm{J}$, et al. Understanding context in knowledge translation: a concept analysis study protocol. J Adv Nurs. 2015;71(5):1146-55.

35. World Health Organization. mhGAP intervention guide for mental, neurological and substance use disorders in non-specialized health settings. Geneva: World Health Organization; 2010.

36. Barbui C, Dua T, van Ommeren M, Yasamy MT, Fleischmann A, Clark $\mathrm{N}$, et al. Challenges in developing evidence-based recommendations using the GRADE approach: the case of mental, neurological, and substance use disorders. PLoS Med. 2010;7(8):e1000322.

37. Dua T, Barbui C, Clark N, Fleischmann A, Poznyak V, van Ommeren M, et al. Evidence-based guidelines for mental, neurological, and substance use disorders in low- and middle-income countries: summary of WHO recommendations. PLoS Med. 2011;8(11):e1001122.

38. Abdulmalik J, Kola L, Fadahunsi W, Adebayo K, Yasamy MT, Musa E, et al. Country contextualization of the mental health gap action programme intervention guide: a case study from Nigeria. PLoS Med. 2013;10(8):e1001501.

39. Keynejad RC, Dua T, Barbui C, Thornicroft G. WHO Mental Health Gap Action Programme (mhGAP) Intervention Guide: a systematic review of evidence from low and middle-income countries. Evid Based Ment Health. 2018;21(1):30-4.

40. World Health Organization. mhGAP intervention guide for mental, neurological and substance use disorder in non-specialised health settings Version 2.0. Geneva: World Health Organization; 2016.

41. May C, Finch T, Mair F, Ballini L, Dowrick C, Eccles M, et al. Understanding the implementation of complex interventions in health care: the normalization process model. BMC Health Serv Res. 2007;7:148.

42. Shidhaye R. Implementation Science for closing the treatment gap for mental disorders by translating evidence base into practice: experiences from the PRIME project. Australas Psychiatry. 2015;23(6 Suppl):35-7.

43. Rathod S, Persaud A, Naeem F, Pinninti N, Tribe R, Eylem Ö, Gorczynski P, Phiri P, Husain N, Muzaffar S, Irfan M. Culturally adapted interventions in mental health: global position statement. World Cult Psychiatry Res Rev. 2020;14(1-2):21-9.

44. Gavlak D. Learning to heal minds in the eastern Mediterranean. Bull World Health Organ. 2016;94(10):714-5.

45. Jha A, Sapkota N. Dementia assessment and management protocol for doctors in Nepal. JNMA J Nepal Med Assoc. 2013;52(189):292-8.

46. Beaglehole R, Epping-Jordan J, Patel V, Chopra M, Ebrahim S, Kidd M, et al. Improving the prevention and management of chronic disease in low-income and middle-income countries: a priority for primary health care. Lancet. 2008:372(9642):940-9.

47. Johnstone A, Goldberg D. Psychiatric screening in general practice. A controlled trial. Lancet. 1976:1(7960):605-8.

48. Meng Q, Yang H, Chen W, Sun Q, Liu X. People's Republic of China health system review. Health systems in transition, Asia Pacific observatory on health systems and policies. WHO South East Asia J Public Health. 2015;5(7):5-12.

49. Chen H, Phillips M, Cheng H, Chen Q, Chen X, Fralick D, et al. Mental Health Law of the People's Republic of China (English translation with 
annotations): translated and annotated version of China's new Mental Health Law. Shanghai Arch Psychiatry. 2012;24(6):305-21.

50. Wang X, Sun X, Birch S, Gong F, Valentijn P, Chen L, et al. Peoplecentred integrated care in urban China. Bull World Health Organ. 2018;96(12):843-52

51. Cheng HG, Shidhaye R, Charlson F, Deng F, Lyngdoh T, Chen S, et al. Social correlates of mental, neurological, and substance use disorders in China and India: a review. Lancet Psychiatry. 2016;3(9):882-99.

52. Kleinman A. Introduction: remaking the moral person in a new China. In Deep China: The moral life of the person, by Arthur Kleinman, Yunxiang Yan, Jing Jun, Sing Lee, Everett Zhang, Pan Tianshu, Wu Fei, Jinhua Guo: University of California Press; 2011.

53. Parker G, Gladstone G, Chee KT. Depression in the planet's largest ethnic group: the Chinese. Am J Psychiatry. 2001;158(6):857-64.

54. Sing L. Chapter five: depression: coming of age in China. In the moral life of the person, by Arthur Kleinman, Yunxiang Yan, Jing Jun, Sing Lee, Everett Zhang, Pan Tianshu, Wu Fei, Jinhua Guo Uniersity of California Press; 2011.

55. Lund C, Tomlinson M, Patel V. Integration of mental health into primary care in low- and middle-income countries: the PRIME mental healthcare plans. Br J Psychiatry. 2016;208(Suppl 56):s1-3.

56. Hanlon C, Fekadu A, Jordans M, Kigozi F, Petersen I, Shidhaye R, et al. District mental healthcare plans for five low- and middle-income countries: commonalities, variations and evidence gaps. Br J Psychiatry. 2016;208(Suppl 56):s47-54.

57. Bitta MA, Kariuki SM, Omar A, Nasoro L, Njeri M, Kiambu C, et al. Contextualizing and pilot testing the Mental Health Gap Action Programme Intervention Guide (mhGAP-IG) to primary healthcare workers in Kilifi, Kenya. Glob Ment Health (Camb). 2020;7:e11.

58. Spagnolo J, Champagne F, Leduc N, Melki W, Guesmi I, Bram N, et al. Tailoring a training based on the Mental Health Gap Action Programme (mhGAP) Intervention Guide (IG) to Tunisia: process and relevant adaptations. Glob Ment Health (Camb). 2018:5:e17.

59. Mutiso VN, Gitonga I, Musau A, Musyimi CW, Nandoya E, Rebello TJ, et al. A step-wise community engagement and capacity building model prior to implementation of mhGAP-IG in a low- and middleincome country: a case study of Makueni County, Kenya. Int J Ment Health Syst. 2018;12:57.

60. Akins RB, Tolson H, Cole BR. Stability of response characteristics of a Delphi panel: application of bootstrap data expansion. BMC Med Res Methodol. 2005;5:37.

61. Okoli C, Pawlowski S. The Delphi method as a research tool: an example, design considerations and applications. Inf Manag. 2004;42:15-29.

62. Surowiecki J. The wisdom of crowds: why the many are smarter than the few. London: Abacus; 2004.

63. Jorm AF. Using the Delphi expert consensus method in mental health research. Aust N Z J Psychiatry. 2015;49(10):887-97.

64. Goodyear M, Hill TL, Allchin B, McCormick F, Hine R, Cuff R, et al. Standards of practice for the adult mental health workforce: meeting the needs of families where a parent has a mental illness. Int J Ment Health Nurs. 2015;24(2):169-80.

65. Ross A, Hart L, Jorm A, et al. Development of key messages for adolesents on providing basic mental health first aid to peers: a Delphi consensus study. Early Interv Psychiatry. 2012;6:229-38.

66. de Mello G, Fraser F, Nicoll P, Ker J, Green G, Laird C. Mental health care training for practitioners in remote and rural areas. Clin Teach. 2013;10(6):384-8.

67. Monash.edu. Shenzhen general practice clinical leadership training 2018. https://www.monash.edu/healthed-institute/short-courses/ shenzhen-general-practice-clinical-leadership-training.

68. McGorry P, van Os J. Redeeming diagnosis in psychiatry: timing versus specificity. Lancet. 2013;381(9863):343-5.

69. Phillips MR. Can China's new mental health law substantially reduce the burden of illness attributable to mental disorders? Lancet. 2013;381(9882):1964-6.

70. Tong Y, Phillips MR, Yin Y, Lan Z. Relationship of the high proportion of suicidal acts involving ingestion of pesticides to the low maleto-female ratio of suicide rates in China. Epidemiol Psychiatr Sci. 2020;29:e114

71. Jiang H, Niu L, Hahne J, Hu M, Fang J, Shen M, et al. Changing of suicide rates in China, 2002-2015. J Affect Disord. 2018;240:165-70.
72. Lu S, Li W, Oldenburg B, Wang Y, Jorm AF, He Y, et al. Cultural adaptation of the mental health first aid guidelines for assisting a person at risk of suicide to China: a Delphi expert consensus study. BMC Psychiatry. 2020;20(1):454.

73. Ferenchick EK, Ramanuj P, Pincus HA. Depression in primary care: part 1-screening and diagnosis. BMJ. 2019;365:1794.

74. Zhang L, Cao XL, Wang SB, Zheng W, Ungvari GS, Ng CH, et al. The prevalence of bipolar disorder in China: a meta-analysis. J Affect Disord. 2017:207:413-21.

75. Chen PL, Li F, Harmer P. Healthy China 2030: moving from blueprint to action with a new focus on public health. Lancet. 2019;4:e447.

76. Minas S. Chapter 8, China's mental health law. Anthony J. Marsella A, GA, USA, editor. USA: Springer; 2021.

77. Dixon LB, Schwarz EC. Fifty years of progress in community mental health in US: the growth of evidence-based practices. Epidemiol Psychiatr Sci. 2014;23(1):5-9.

78. Drake RE, Latimer E. Lessons learned in developing community mental health care in North America. World Psychiatry. 2012;1 1(1):47-51.

79. Liang C, Mei J, Liang Y, Hu R, Li L, Kuang L. The effects of gatekeeping on the quality of primary care in Guangdong Province, China: a crosssectional study using primary care assessment tool-adult edition. BMC Fam Pract. 2019;20(1):93.

80. Lu S, Li W, Oldenburg B, Wang Y, Jorm AF, He Y, et al. Cultural adaptation of the mental health first aid guidelines for depression used in English-speaking countries for China: a Delphi expert consensus study. BMC Psychiatry. 2020;20(1):336.

81. Atsmon Y, Magni M. Meet the Chinese consumer of 2020. McKinsey Quarterly. 2012.

82. Wu Z, Fang Y. Comorbidity of depressive and anxiety disorders: challenges in diagnosis and assessment. Shanghai Arch Psychiatry. 2014:26(4):227-31.

83. World Health Organization. Framework on integrated, people-centred health services. WHO; 2016.

84. World Health Organization. Framework on integrated people-centred health services: an overview 2016. https://www.who.int/servicedel iverysafety/areas/people-centred-care/Overview_IPCHS_final.pdf? $\mathrm{ua}=1$.

85. Luo H, McNeil EB, Feng Q, Li H, Chen Q, Qin X, et al. Utilization of psychiatric rehabilitation services and influencing factors among people with psychotic disorders in rural communities of Guangxi, China. Int J Ment Heal Syst. 2018;12(1):17.

86. Stewart MA. Effective physician-patient communication and health outcomes: a review. CMAJ. 1995;152(9):1423-33.

87. Kim SS, Kaplowitz S, Johnston MV. The effects of physician empathy on patient satisfaction and compliance. Eval Health Prof. 2004:27(3):237-51.

88. Mercer SW, Neumann M, Wirtz M, Fitzpatrick B, Vojt G. General practitioner empathy, patient enablement, and patient-reported outcomes in primary care in an area of high socio-economic deprivation in Scotland-a pilot prospective study using structural equation modeling. Patient Educ Couns. 2008;73(2):240-5.

89. Li D, Xu H, Kang M, Ma S. Empathy in Chinese eight-year medical program students: differences by school year, educational stage, and future career preference. BMC Med Educ. 2018;18(1):241.

90. Pun JKH, Chan EA, Wang S, Slade D. Health professional-patient communication practices in East Asia: an integrative review of an emerging field of research and practice in Hong Kong, South Korea, Japan, Taiwan, and Mainland China. Patient Educ Couns. 2018;101 (7):1193-206.

91. Zou G, Wei X. A qualitative study of two management models of community health centres in two Chinese megacities. Glob Public Health. 2018;13(11):1612-24.

92. Bi Q, Wu Y, Mei S, Ye C, Zou X, Zhang Z, et al. Epidemiology and transmission of COVID-19 in 391 cases and 1286 of their close contacts in Shenzhen, China: a retrospective cohort study. Lancet Infect Dis. 2020;20(8):911-9.

93. Li Q, Guan X, Wu P, Wang X, Zhou L, Tong Y, et al. Early transmission dynamics in Wuhan, China, of novel coronavirus-infected pneumonia. N Engl J Med. 2020;382(13):1199-207.

94. World Health Organization. COVID-19 Public Health Emergency of International Concern (PHEIC) Global research and innovation forum. 2020 12/02/2020 
95. Zou H, Shu Y, Feng T. How Shenzhen, China avoided widespread community transmission: a potential model for successful prevention and control of COVID-19. Infect Dis Poverty. 2020;9(1):89.

96. Walker T. China-Australia relations hit new low in spat over handling of coronavirus Australia2020. https://theconversation.com/china-australiarelations-hit-new-low-in-spat-over-handling-of-coronavirus-137377.

97. Doran M, Henderson A. Scott Morrison defends Peter Dutton's calls for transparency from China over the origins of coronavirus. ABC News. 2020 23/04/2020

98. ABC. China warns citizens not to travel to Australia amid 'increased' racismsince coronavirus outbreak. ABC News. 2020 6/06/2020.

99. Tan S. Why has the China-Australia relationship deteriorated into 'trade war 2.0'? South Morning China Post, The. 2020 1/07/2020.

100. Howarth E, Vainre M, Humphrey A, Lombardo C, Hanafiah AN, Anderson JK, et al. Delphi study to identify key features of community-based child and adolescent mental health services in the East of England. BMJ Open. 2019;9(6):e022936.

101. Tyler N, Wright N, Grundy A, Waring J. Developing a core outcome set for interventions to improve discharge from mental health inpatient services: a survey, Delphi and consensus meeting with key stakeholder groups. BMJ Open. 2020;10(5):e034215.

\section{Publisher's Note}

Springer Nature remains neutral with regard to jurisdictional claims in published maps and institutional affiliations.

- fast, convenient online submission

- thorough peer review by experienced researchers in your field

- rapid publication on acceptance

- support for research data, including large and complex data types

- gold Open Access which fosters wider collaboration and increased citations

- maximum visibility for your research: over $100 \mathrm{M}$ website views per year

At BMC, research is always in progress.

Learn more biomedcentral.com/submissions 